\title{
Editorial: Insect Fertility in a Changing Environment
}

\author{
Alison McAfee ${ }^{1,2 *}$, Jonathon H. Stillman ${ }^{3,4,5}$, Katie E. Marshall ${ }^{6}$ and Bradley N. Metz ${ }^{2}$ \\ ${ }^{1}$ Michael Smith Laboratories, Department of Biochemistry and Molecular Biology, University of British Columbia, Vancouver, \\ BC, Canada, ${ }^{2}$ Department of Applied Ecology, North Carolina State University, Raleigh, NC, United States, ${ }^{3}$ Department of \\ Biology, San Francisco State University, San Francisco, CA, United States, ${ }^{4}$ Department of Integrative Biology, University of \\ California, Berkeley, Berkeley, CA, United States, ${ }^{5}$ Department of Environmental Sciences, University of Basel, Basel, \\ Switzerland, ${ }^{6}$ Department of Zoology, University of British Columbia, Vancouver, BC, Canada
}

Keywords: insects, fertility, stressors, population, mating

\section{Editorial on the Research Topic}

\section{Insect Fertility in a Changing Environment}

Insects are integral for sustaining healthy ecosystems, offering pollination services, nutrient cycling, and plant control through herbivory, among other essential functions (Losey and Vaughan, 2006). They are also a massive source of food for predators. Although they often go unnoticed and are sometimes considered to be pests, their cumulative ecosystem services are invaluable. While some recent surveys and historical records have indicated declines in insect taxa (Biesmeijer et al., 2006; Hallmann et al., 2017; Møller, 2019; Bell et al., 2020; Van Klink et al., 2020), the specific drivers remain unclear (Goulson, 2019; Sánchez-Bayo and Wyckhuys, 2019). To better understand insect population trends, we believe a mechanistic understanding of how insect fertility may be changing is essential.

Potential environmental drivers of changes in insect abundance and fertility vary by taxa and region, but can broadly be categorized into pest and pathogen pressure, effects of climate change, competition from invasive species, pollution (particularly from pesticides and fertilizers), and habitat loss from urbanization and intensive agriculture (Sánchez-Bayo and Wyckhuys, 2019). In our rapidly changing environment, there is a critical need to understand how human-driven changes in biotic and abiotic conditions are affecting insects' abilities to survive and reproduce (Figure 1).

While there is significant debate over insect population abundance changes (Thomas et al., 2019; Beck and McCain, 2020; Bell et al., 2020; Guzman et al., 2021; Welti et al., 2021), we argue that understanding the mechanisms that could lead to population decline is still is a critical step toward mitigating the pressures imposed on entomofauna. In this special issue, we highlight research on factors affecting insect fertility - a characteristic that is clearly necessary to maintain viable populations. The contributing researchers test how pesticides, parasites, disease, genetics, and extreme temperatures could affect outcomes linked to fertility in social insects. Together, this body of work challenges our assumptions and extends the frontier of knowledge in three key areas for reproductive individuals: immunocompetence, development, and behavior.

All the study species in this issue are social insects, including leafcutter ants (Atta colombica), bumble bees (Bombus terrestris), and honey bees (Apis mellifera). Although we acknowledge the 


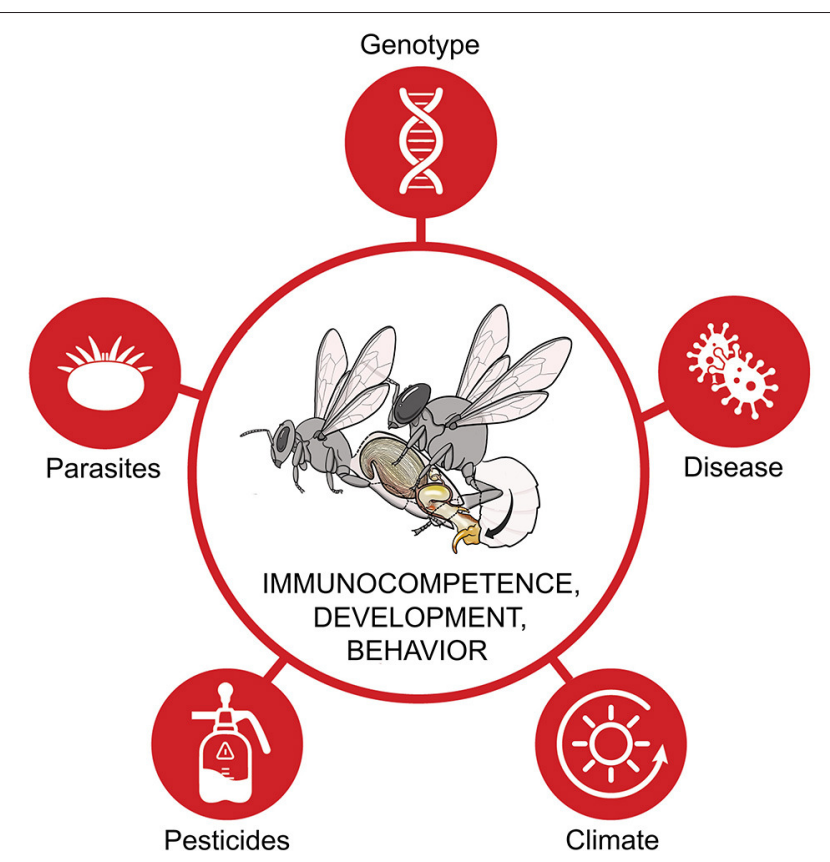

FIGURE 1 | Factors affecting insects' abilities to survive and reproduce. Research in this special issue addresses how parasites, genetics, diseases, climate change, pesticides, and, in some cases, their interactions, can impact insect lifespan and fertility. Other factors, such as competition and habitat loss, are also important but are not addressed here. Artist: Kirsten Bensen.

need for research on social and solitary insects, fertility of social insects is of particular interest, owing to their relative abundance (ant and termites make up nearly a third of animal biomass in the Amazon rainforest, for example (Hölldobler and Wilson, 1990), reproductive division of labor, and, in the case of the bees, their utility in an agricultural setting.

Among social insects, a disproportionate volume of fertility research focuses on queen biology. Male (drone) fertility is obviously also a key factor for reproduction, but it is too often neglected. Bruckner et al. help to fill this knowledge gap by investigating effects of Varroa destructor (a parasitic mite) and neonicotinoid pesticides on male honey bees exposed during development. Worryingly, the researchers show that these stressors interact synergistically to lower male bee survival, reducing the number of males available for mating.

Although male honey bees are often more sensitive to stressors than females (Friedli et al., 2020; McAfee et al., 2021), they still possess defense and tolerance mechanisms. Holt et al. investigated interactions between microsporidian parasite Vairimorpha apis [formerly Nosema apis (Tokarev et al., 2020)], and male honey bees, with the goal of determining if genetically distinct drones differed in their susceptibility to the parasite, and if tolerance could be linked to antifungal immune effectors (chitinases) in seminal fluid. The researchers identified strong colony effects on susceptibility to the microsporidian. Since this is a sexually transmitted disease, the work highlights the importance of carefully selecting drone source colonies during industrial queen production.

Parasites and toxins can have overt effects on insect physiology, but an angle not often considered is that exposure to stressors could also alter mating behavior. Przybyla et al. describe a novel method to evaluate how unmated $B$. terrestris queens respond to males that have experienced extreme heat-a scenario that is expected to increase in frequency due to climate change (Meehl and Tebaldi, 2004). B. terrestris is a warm-adapted species (Martinet et al., 2021), and the authors found no impact of heat on male attractiveness, copulation behavior, or brood development. Applying this method to evaluating the mating behaviors of more heat-sensitive species will be an important area of future research to understand how climate change may alter mating behavior.

After mating, social insect queens store the sperm they have acquired in a specialized storage organ called a spermatheca-a process thought to be energetically costly for the queen (Baer et al., 2006), possibly making her vulnerable to secondary stressors. Baer et al. tracked queen health metrics (body mass, immunocompetence, and survival) in A. colombica queens after artificial insemination with either a sham, sperm only, seminal fluid only, or full ejaculate. Although obviously necessary for reproduction, queens receiving sperm had lower survival than queens that did not receive sperm, supporting the idea that sperm storage incurs a cost. Lightweight queens and those losing body mass during the experiment had poor survival and low immunocompetence, respectively, further suggesting that queens may be exceptionally vulnerable to additional stressors and pathogenic infections after mating.

In eusocial colonies, queen fecundity is not only impacted by direct effects of stress, it is also influenced by the behavior of the sterile worker caste. In two complementary approaches, Litsey et al. investigated how worker exposure to pesticides (insect growth regulators, or IGRs) during development may alter their subsequent behavior toward their queen, whereas Walsh et al. tested how queen exposure to pesticides (three types of miticides, a fungicide, and an insecticide) could impact worker propensity to tend the queens. Of the three IGRs tested by Litsey et al. two altered worker responsiveness to the queen, highlighting potential knock-on effects of worker exposure on perceived queen quality. Surprisingly, Walsh et al. found no effect of queen developmental exposures, which contradicts existing data (Walsh et al., 2020; Milone and Tarpy, 2021), and highlights the need for robust replication.

Although the Anthropocene poses many challenges for insect fertility, the outlook painted by this body of research is far from bleak. We see that mating behavior of male $B$. terrestris is not significantly impacted by heat exposure, that male honey bees exhibit variable but effective immune responses to a sexually transmitted parasite, and that, contrary to prior evidence, queen honey bee exposure to pesticides during development does not necessarily impact them negatively. However, the struggle to survive is clear in other areas: Some stressors interact synergistically to reduce drone honey bee survival, IGR pesticides can indirectly impact queen honey bees through disrupted 
worker care, and the very act of mating leaves A. colombica queens vulnerable to death and disease.

The impacts of human-induced environmental change on fertility are clearly both complex and consequential. While the research presented here provides a glimpse into the complexity of changing insect fertility, it is clear that insects are also extremely plastic. Therefore, when possible, mechanistic investigations are necessary to parse potential outcomes. We call on our community of researchers to continue exploring this area, with the goal of identifying general principles underlying impacts on insect fertility.

\section{REFERENCES}

Baer, B., Armitage, S. A., and Boomsma, J. J. (2006). Sperm storage induces an immunity cost in ants. Nature $441,872-875$. doi: $10.1038 /$ nature 04698

Beck, J., and McCain, C. M. (2020). Just bird food?-on the value of invertebrate macroecology. Front. Biogeogr. 12:4784. doi: 10.21425/F5FBG47684

Bell, J. R., Blumgart, D., and Shortall, C. R. (2020). Are insects declining and at what rate? an analysis of standardised, systematic catches of aphid and moth abundances across great britain. Insect. Conserv. Divers. 13, 115-126. doi: $10.1111 /$ icad. 12412

Biesmeijer, J. C., Roberts, S. P., Reemer, M., Ohlemüller, R., Edwards, M., Peeters, T., et al. (2006). Parallel declines in pollinators and insectpollinated plants in Britain and the Netherlands. Science 313, 351-354. doi: $10.1126 /$ science. 1127863

Friedli, A., Williams, G. R., Bruckner, S., Neumann, P., and Straub, L. (2020). The weakest link: Haploid honey bees are more susceptible to neonicotinoid insecticides. Chemosphere 242:125145. doi: 10.1016/j.chemosphere.2019.125145

Goulson, D. (2019). The insect apocalypse, and why it matters. Curr. Biol. 29, R967-R971. doi: 10.1016/j.cub.2019.06.069

Guzman, L. M., Johnson, S. A., Mooers, A. O., and M'gonigle, L. K. (2021). Using historical data to estimate bumble bee occurrence: Variable trends across species provide little support for community-level declines. Biol. Conserv. 257:109141. doi: 10.1016/j.biocon.2021.109141

Hallmann, C. A., Sorg, M., Jongejans, E., Siepel, H., Hofland, N., Schwan, H., et al. (2017). More than 75 percent decline over 27 years in total flying insect biomass in protected areas. PLOS ONE 12:e0185809. doi: 10.1371/journal.pone.0185809

Hölldobler, B., and Wilson, E. O. (1990). The Ants. New York, NY: Harvard University Press.

Losey, J. E., and Vaughan, M. (2006). The economic value of ecological services provided by insects. AIBS Bull. 56, 311-323. doi: 10.1641/0006-3568(2006)56311:TEVOES2.0.CO;2

Martinet, B., Zambra, E., Przybyla, K., Lecocq, T., Anselmo, A., Nonclercq, D., et al. (2021). Mating under climate change: Impact of simulated heatwaves on the reproduction of model pollinators. Funct. Ecol. 35, 739-752. doi: $10.1111 / 1365-2435.13738$

McAfee, A., Metz, B., Milone, J. P., Foster, L. J., and Tarpy, D. R. (2021). Drone honey bees are disproportionately sensitive to abiotic stressors despite expressing high levels of stress response proteins. bioRxiv 2021.2008.2028.456261. doi: 10.21203/rs.3.rs-829028/v1

Meehl, G. A., and Tebaldi, C. (2004). More intense, more frequent, and longer lasting heat waves in the 21st century. Science 305, 994-997. doi: $10.1126 /$ science.1098704

Milone, J. P., and Tarpy, D. R. (2021). Effects of developmental exposure to pesticides in wax and pollen on honey bee (Apis mellifera) queen reproductive phenotypes. Sci. Rep. 11:1020. doi: 10.1038/s41598-020-80446-3

\section{AUTHOR CONTRIBUTIONS}

$\mathrm{AM}$ and $\mathrm{BM}$ wrote the first draft. BM and $\mathrm{KM}$ edited the manuscript. KM and JS advised the other authors. All authors reviewed and approved of the manuscript.

\section{FUNDING}

KM was supported by a Natural Sciences and Engineering Research Council Discovery Grant and AM was supported by a L'Oréal-UNESCO Research Excellence Fellowship.

Møller, A. P. (2019). Parallel declines in abundance of insects and insectivorous birds in Denmark over 22 years. Ecol. Evol. 9, 6581-6587. doi: 10.1002/ece3. 5236

Sánchez-Bayo, F., and Wyckhuys, K. A. (2019). Worldwide decline of the entomofauna: a review of its drivers. Biol. Conserv. 232, 8-27. doi: 10.1016/j.biocon.2019.01.020

Thomas, C. D., Jones, T. H., and Hartley, S. E. (2019). "Insectageddon": a call for more robust data and rigorous analyses. Glob. Chang Biol. 25, 1891-1892. doi: $10.1111 /$ gcb. 14608

Tokarev, Y. S., Huang, W.-F., Solter, L. F., Malysh, J. M., Becnel, J. J., and Vossbrinck, C. R. (2020). A formal redefinition of the genera Nosema and Vairimorpha (Microsporidia: Nosematidae) and reassignment of species based on molecular phylogenetics. J. Invert. Path. 169:107279. doi: 10.1016/j.jip.2019.10 7279

Van Klink, R., Bowler, D. E., Gongalsky, K. B., Swengel, A. B., Gentile, A., and Chase, J. M. (2020). Meta-analysis reveals declines in terrestrial but increases in freshwater insect abundances. Science 368, 417-420. doi: 10.1126/science.aax 9931

Walsh, E. M., Sweet, S., Knap, A., Ing, N., and Rangel, J. (2020). Queen honey bee (Apis mellifera) pheromone and reproductive behavior are affected by pesticide exposure during development. Behav. Ecol. Sociobiol. 74, 1-14. doi: 10.1007/s00265-020-2810-9

Welti, E. A. R., Joern, A., Ellison, A. M., Lightfoot, D. C., Record, S., Rodenhouse, N., et al. (2021). Studies of insect temporal trends must account for the complex sampling histories inherent to many long-term monitoring efforts. Nat. Ecol. Evol. 5, 589-591. doi: 10.1038/s41559-021-01424-0

Conflict of Interest: The authors declare that the research was conducted in the absence of any commercial or financial relationships that could be construed as a potential conflict of interest.

Publisher's Note: All claims expressed in this article are solely those of the authors and do not necessarily represent those of their affiliated organizations, or those of the publisher, the editors and the reviewers. Any product that may be evaluated in this article, or claim that may be made by its manufacturer, is not guaranteed or endorsed by the publisher.

Copyright (c) 2022 McAfee, Stillman, Marshall and Metz. This is an open-access article distributed under the terms of the Creative Commons Attribution License (CC $B Y)$. The use, distribution or reproduction in other forums is permitted, provided the original author(s) and the copyright owner(s) are credited and that the original publication in this journal is cited, in accordance with accepted academic practice. No use, distribution or reproduction is permitted which does not comply with these terms. 